\title{
Surgery, fields, and phenomena
}

\author{
Martin Riegler
}

Published online: 23 April 2019

(c) Springer-Verlag GmbH Austria, part of Springer Nature 2019

\section{Dear reader,}

Welcome to this issue of European Surgery. Here, the team of experts around the Austrian surgeon Stefan Stättner have orchestrated a well-structured, written, and tuned spectrum of papers dealing with the surgical management of benign and malignant pancreatic disease including minimally invasive surgery, integrated interdisciplinary medicine, and oncology. The papers are highly recommended to those who are involved in the management of pancreatic disease and cancer treatment. May the papers enrich your knowledge and comfort the management of your patients. The authors are to be congratulated for their passion and endurance in providing highquality science, teaching, and education.

\section{Surgery, myth, and science}

In the recent issues of European Surgery we examined how much myth, medicine, surgery, diagnosis, therapy, and the conduct of disease management share a common character and quality. Basically, myth and medicine operate by converting images, perceptions, and awareness into treatable signs. Thus, both myth, science, and medicine use fundamental semiotic mechanisms to achieve their goals: to unhide the hidden, to reveal the unknown for the benefit of life quality, wellbeing, and productivity of an individual or a given population. Scientific studies aim to collect (logos), order (mathematics), socialize (ethics, science), enlarge, foster, save, and maintain perceptions for the next generations (academy). Based on the collected knowledge (logos), science develops and

\section{Doz. Dr. M. Riegler $(\bowtie)$}

Reflux Medical, Mariannengassse 10/9, 1090 Wien, Austria martin.riegler@refluxmedical.com publishes recommendations and guidelines for diagnosis, therapy, and disease management. However, guidelines should always be critically viewed and questioned. Otherwise the blind followers of guidelines could become victims of uncritical reasoning and foster a crucial form of despotism. Why this happens? Science roots within the interests of multiple industries and will for power networks (technologies, industry, personal, internet).

Conceptually, in addition to serving as a tool for practical medicine, guidelines represent a specific manifestation of will to power: the ruling opinion. One says, one does, one thinks, one acts, one sees, one rules, and therefore one justifies her or his existence. Thus, the basic mechanisms for the operation of guidelines and despotism systems are the same. Let us see how that works. Who is the "one"? You, me, a grey undefinable mass of people?

Whenever people followed a so-called ruling opinion, it turned out to happen against the benefit of the majority and for the advantage of a minority, i.e., the ruling class [1-3]. For example, those who followed the ruling opinion in their lifetimes were those who had lost their lives during wars: First, Second World War, Korean War, Vietnam War, the wars of Afghanistan, Iran, Iraq, Yugoslavia, etc. Those who followed the ruling opinion of their times created the victims of the holocaust, the atomic bomb, and all war, crime, and destruction around the world [1-3]. Although history proves that the uncritical "belief" in ruling opinions causes adverse effects and consequences for human civilization, people continue to fall into the fundamental trap and repeat the mistakes of their forefathers, creating pain, sorrow, and destruction. It remains to be questioned, why man to man is so unjust, why your best friend becomes your greatest enemy, why your social networks break 
apart and release the most negative energies including greed, envy, hate, and hunger [1-3].

\section{Archaion}

Phenomenologically, the formatting of our individual perceptions underlies the mechanisms and views of the will to power. As a must, any perceivable system, structure, and algorithm aims to get bigger, larger, greater, more important, in order to increase power, strength, influence, might, and control over other well or less defined systems (i.e., fragments of the universe). Within the brain of the beautiful human being there resides a field of energy, which controls our behavior, reasoning, decision-making: the archaion! For millions of years our forefathers and foremothers have benefitted from the activities generated and fostered by the archaion. The archaion helped us to find out to use the fire, the environment for the benefit of our wellbeing and prosperity. The archaion created our interaction with the phenomenon named will for power. As such, we made it to set the stage on our globe for the belief to be the controllers of the globe, the masters of the world, the rulers of the cloud! The archaion fostered the design, creation, and development of fundamental inventions of man. These inventions are of major relevance and significance and should be named within this editorial. Many things that are taken for granted, for taken, are inventions of women and men. Many structures, algorithms, ways of thinking, beliefs, and reasoning are nothing other than simple, creative inventions and innovative creations of our foremothers, fathers, sisters, and brothers.

\section{Inventions}

During an intensive and productive conduct of reasoning, humans invented religions, political and social systems, democracy, technologies, tissues, arms, weapons, architecture, etc., in order to gain better control over their environment and other humans. And this all rooted and still roots within the archaion! Multi-detector positron-emission magnetic resonance tomography orders the energetic fields within a given brain and visualizes the nerve cell groups making up the archaion, i.e., the stem brain connected to the cortex of the hemispheres. There, within the archaion, arise emotions - hate, greed, envy, and hunger-in order to create activities against hunger and greed: go out for food, gain more, run for your life. The archaion contains the structures and nerve cell activities which invented the development of all different kinds of myths, including religions, social grouping, networks, and, last but not least: the internet and the web-based slavery of mankind! Well, taken here, we go and ask, "why does that happen?" This happens, because man is an animal that works within groups of 50 to 140 individuals or so. No man is an island. Thus, as gatherers and hunting dogs, human beings always tend to get together and form social, economic, technological, religious, etc., groups. The group formation creates the feelings of security and helps to replace and reduce the individual responsibility for our deeds. Following and serving the principles of the will to power, the ruling opinion invents truth, justice, ethics, and logics, and operates in various beautiful shapes of error in order to justify his/her intentions, which in turn serve the increase of their power, might, influence, and economic benefit. As such, we have been allowed to read and follow the truth since more than 5000 years: "the star says," "the milky way says," "where the dog ran, says," "the creator says," "the priest saw and says," "the king saw and says," "the goddess says and wants," "god says and wants," "the white house says," "the head of a group says," "the leader says," "the boss thinks, says, and orders," "the dean of the academy thinks, says, and wants," "going in line with the guideline, the diagnosis, therapy, and management of a given disease is to be done, performed, please always follow the guideline, the ruling opinion, the ruling view, the prevailing opinion, as a matter of fact, as a matter of truth," and if you allow yourself to doubt and put into question the ruling opinion, you are immediately punished by the majority, which is right, because it serves the ruling opinion and represents the majority. Unfortunately, there exists only a small group of those who oppose the ruling opinion, who critically assess, prove, and put into question the ruling opinion, prevailing view, and conduct of reasoning. Taken together, the ruling opinion represents a manifestation of the archaionbased conduct of reasoning and behavior, following the essential and fundamental principles of the will to power; it offers rules for the majority and this provides security and takes away responsibility from human beings. Going in line with the recent editorials published in European Surgery we, you and me, dear reader, came up with the conclusion that:

- most humans lack discipline

- most humans lack humility

- most humans lack open-minded reasoning

- most humans fear change and innovation

- most humans lack the will to take responsibility

- most humans lack the will to approach others with respect, honor, and fair play

- most humans lack the will to follow the will for essence-based reasoning,

- most humans lack the will to put into question the ruling opinion, view, and guidelines

\section{Trapped within guidelines}

As a consequence, humans are caught within the trap of the manifestations of the will to power, which in turn represent amazing inventions of human conduct of reasoning: despotisms, industries, religions, beliefs, internet, political parties and their programs and 
guidelines. Going in line with the guidelines may work in the majority of cases, but if the case becomes essential, gets crucial, the guidelines may stop to work [4]. As a matter of fact, if the guideline fails to work, stops to prosper, or its help vanishes, insecurity, anxiety, fear, loneliness, vanity may arise [1-3]. You may ask: "what happened?" The reply, the answer: "You got trapped within the poisonous atmosphere of the guideline. "The list of legacies demonstrating and proving the disastrous consequences of uncritical following of a ruling opinion, prevailing view, and guideline, which are in fact nothing else but simple inventions of humans (inventions like cars, computers, games, guitars, pianos, drums, bongos, congas, noise makers, cigarettes, cookies, architecture, paintings, arts and grafts, etc.), who play the will to power game for their benefit and to increase their power, wealth, might, and economic income, range from the times of ancient Egypt, Mesopotamia, India, East Asia, the Americas, Europe, Central Africa, the endless water planes of the Pacific, Indian, and Atlantic oceans, the times of the Ancient Greeks, Romans, the so-called empires and states of the dark Middle Ages (in fact, the middle ages were not dark! The sun did not stop to shine over kings and princesses) to the inventions and innovations of modern European civilization and the accidents of democracy, i.e., the two world wars, the Cold War, the non-solid state of fool and care funding of the present history. And it all happened, because the majority of our people, mothers, fathers, sisters, and brothers follow prevailing guidelines, ruling opinions, without putting them into question.

Here, the academy in Austria and elsewhere should think different, but, unfortunately, the academy does not represent an exception, it usually follows the uncritical conduct of reasoning and blind belief in the stage set by the ruling opinion guidelines in the majority of cases. There only exists a very small number of courageous scientists who are willed to put into question the ruling opinion and critically oppose the ruling view, opinion, and conduct of argumentation [4-10]. Those brave physicians leave the secure path and track and foster the development of novel possibilities for disease management and examination of human history [4-10]. In 20 years or so, the majority will follow their ideas, because the new ideas will have withstood the test of time. Based on the specialty and focus of the author, we will enter a bolus-based example of interest, which demonstrates what happens if we uncritically follow the ruling opinion, the ruling view, the ruling guideline [4-10].

Why do we follow the ruling guideline: we fear to be punished if we stop to do so; in fact, we are cowards, hypocrites, liars, fragmented unimportant pillars of greed, envy, and hate, as foolishness, stupidity, and furtiveness flood out, stream out of our eyes, mouth, tongues, sayings, expressions of any kind including our statements, estimates, writings, talkings, presentations, publications. The cold sweat of anger, fear, and anxiety drops from our hands, faces, chests, legs, and buttocks. Most of us, the majority of us, really made it to become a disastrous, abhorrent, foolish academical species of dregs and drops of hate, greed, and universal stupidity. Maybe, at least sometimes, during short moments or longer periods of weakness, during invaluable temper-induced insecurities, I, the author, also behave as a coward, hypocrite, uncritical observer and follower-could be, cannot be excluded for sure, as nothing is sure, not even my perception, that is the way how the world, reality is made up, unfortunately. Atmosphere equals reasoning equals being equals the moment (Parmenides). Therefore, and due to the fact that nobody is perfect, I openly invite you to come under the protection of the umbrella of my essence-based reasoning. We and you have to ask: why did it all happen to come? What is the reason for our cowardly behavior and lack of humility, discipline, understanding, and open-minded reasoning? Why did we, you and me, fall into the trap of the ruling opinion, the ruling view, the ruling guideline, the ruling manifestation of the will to power?

Today, humans are easily trapped within the brutal arms of the internet-based global network of communication. Humans became the slaves of their invention, the computer-based algorithms decide what humans do, think, reason, select, choose, matter, like, dislike, mean, ask, understand, evolve, feel, struggle, and punish. As a matter of fact, the web-based and web-driven and social media-forced realities leave no time for thinking, for deep reasoning. One is forced to immediately react, answer, reply, and act, going in line with the ruling opinion. There is no space, there is no time to step out of the trap. As such, the easiest way to live is to follow the ruling opinion, to follow the guideline. It is much easier and less time- and brain substance-consuming to follow a guideline, which you may look up in the internet, when compared to living a critical appraisal and conduct of reasoning [1-8]. Trapped within the stress of the daily routine and not protected and covered by the responsibilities of adequate leaders, bosses, and institutions, the employees, medical, and nursing staff have to act in line with the guidelines. If they would try to step out, to allow essence-based reasoning, to oppose the ruling power game-driven guideline and view, they would be kicked out by the arguments of the followers (hypocrites!) of the ruling opinion (diplomatic, calculating), they will not find support and justification for their decisions, since their decisions are against the ruling guidelines. And the ruling guidelines are taken as the truth, are taken as granted, because they are followed by the majority of the academical population (pseudo-science!), and, therefore, it is believed, followed, that the ruling opinion must be correct, right, and good. Taken together, truth represents the justification of the will to power and hypocrites give it the appearance of wisdom (religion), justice (ethics), and knowledge (logos) to hide their wicked intention, to rule others, to gain 


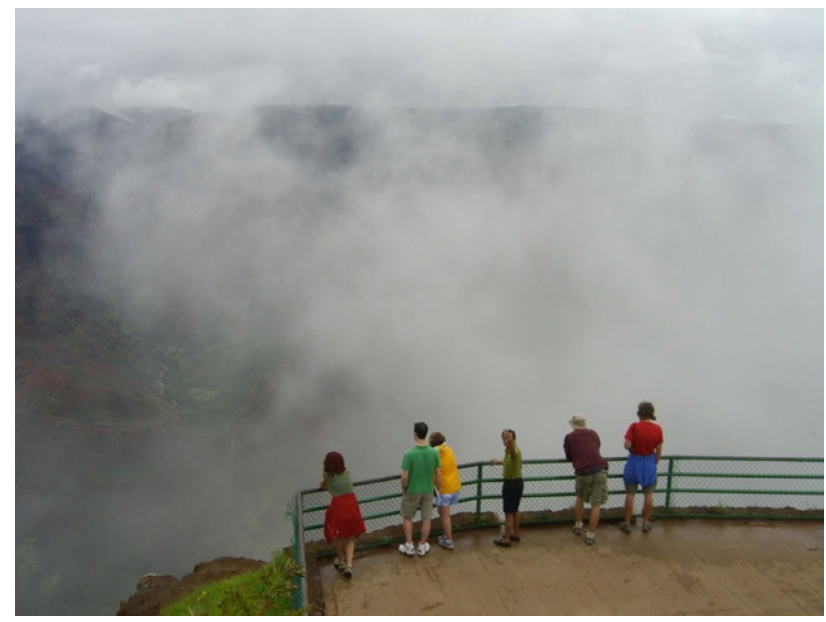

Fig. 1 The image mirrors the idea of the author that the interaction of the energetic fields with our translation mechanisms (eyes, telescopes, microscopes, radio, TV, computers, etc.), which in turn also represent components of the four energetic fields, creates our perceptions in the form of a fragmented perspective, as outlined in the text. Image obtained in Hawaii, USA. The image is centered by the pathologist Prof Dr Para Chandrasoma, whom we owe a novel histopathology classification and a new understanding of gastroesophageal reflux disease and Barrett's esophagus

more power and might over others $[1-4,6]$. As such, academy happens and behaves as other places on our globe, including desserts, seas, mountains, and streams of land, water, and air. In conclusion, our world, our globe still takes us with passion and represents a small, tiny, distinct spherical cloud of beauty, the only place where we are able to live as humans, as people, as women, men, as followers of guidelines and ruling powers. As such, the opening of our minds created the heavens and the earth. What does "heavens" mean? Does the term "heavens" translate, transport, carry a deep wisdom of legacy from a lost ancient civilization, which may have been the precursor of our present civilization, which may have been wiped out by a gigantic cataclysm asteroid impact 12,000 years ago, as suggested by Graham Hancock et al? [6-8].

\section{Fields}

Maybe the "heavens" model the current understanding of physics. Going in line with the current understanding, all we perceive are segmental manifestations of four different fields:

- the Higgs field, i.e., space time; gravity

- the electromagnetic field,

- the strong nuclear power,

- the weak nuclear power.

These fields extend throughout the so-called universe and get into our vision and perception via our sensations (sight, smell, etc.; Fig. 1). During perception we interact with the fields and thus create the phenomena of particles, masses, stars, planets, etc. And there is the enormous armamentarium of translation machines and mechanisms, which allow us to interact with these fields at the small and large scale. And during the interaction (Hubble telescope, CERN, etc.) we envision the visualization and modelling of these interactions in the form of waves, particles, forces, space-time curving, light, mass, energy. Going in line
Fig. 2 Antegrade (panels $\mathbf{a}, \mathbf{c )}$ and retrograde (panels b, d) endoscopic view towards the esophagogastric junction in individuals with atypical (cough, wheezing, globus sensation; a, b) and typical (heartburn, regurgitation) symptoms (c, d) of gastroesophageal reflux disease. Retrograde endoscopic appearance (b, d) indicates failure of the lower esophageal sphincter, as outlined in the text
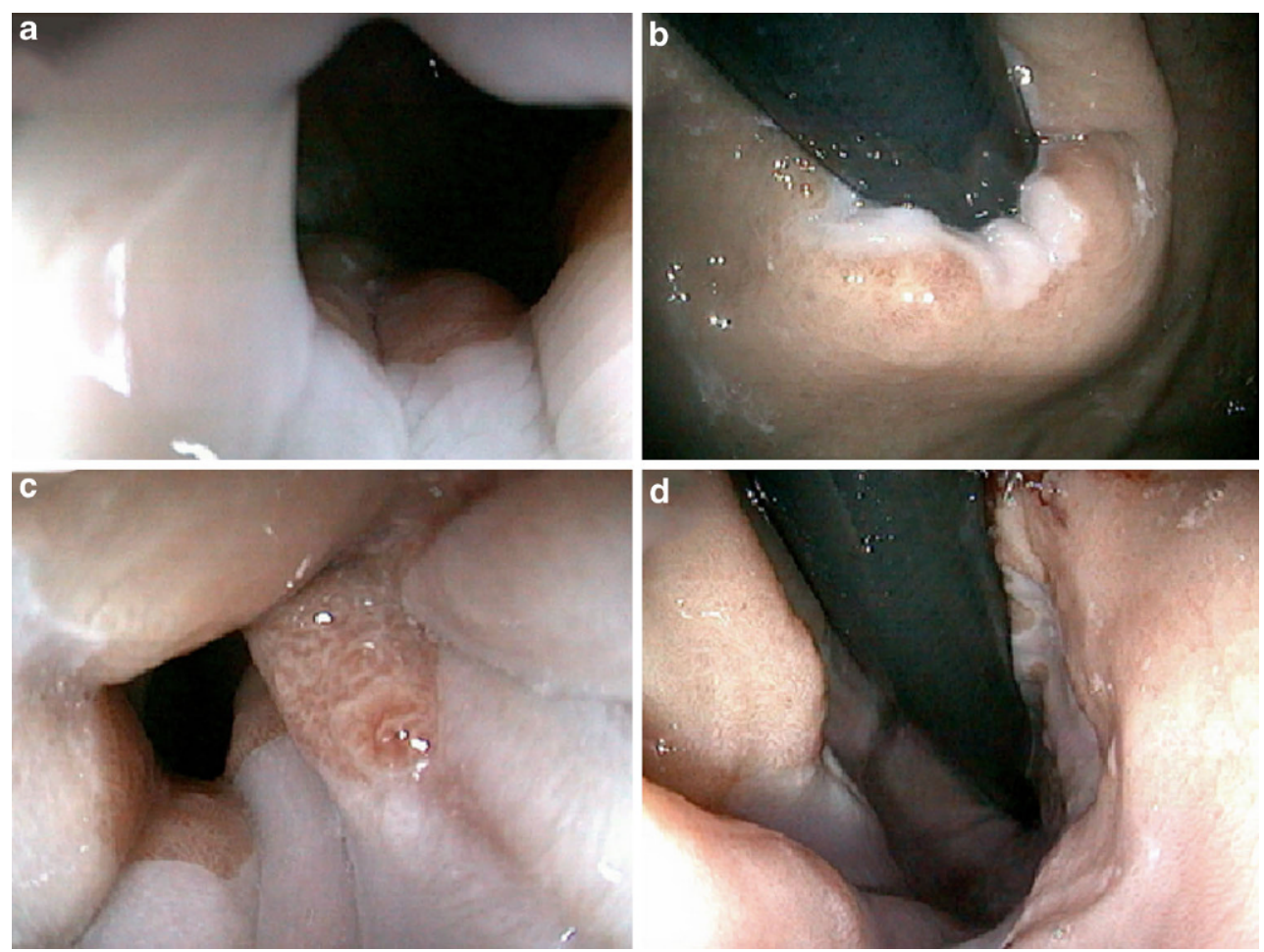
a
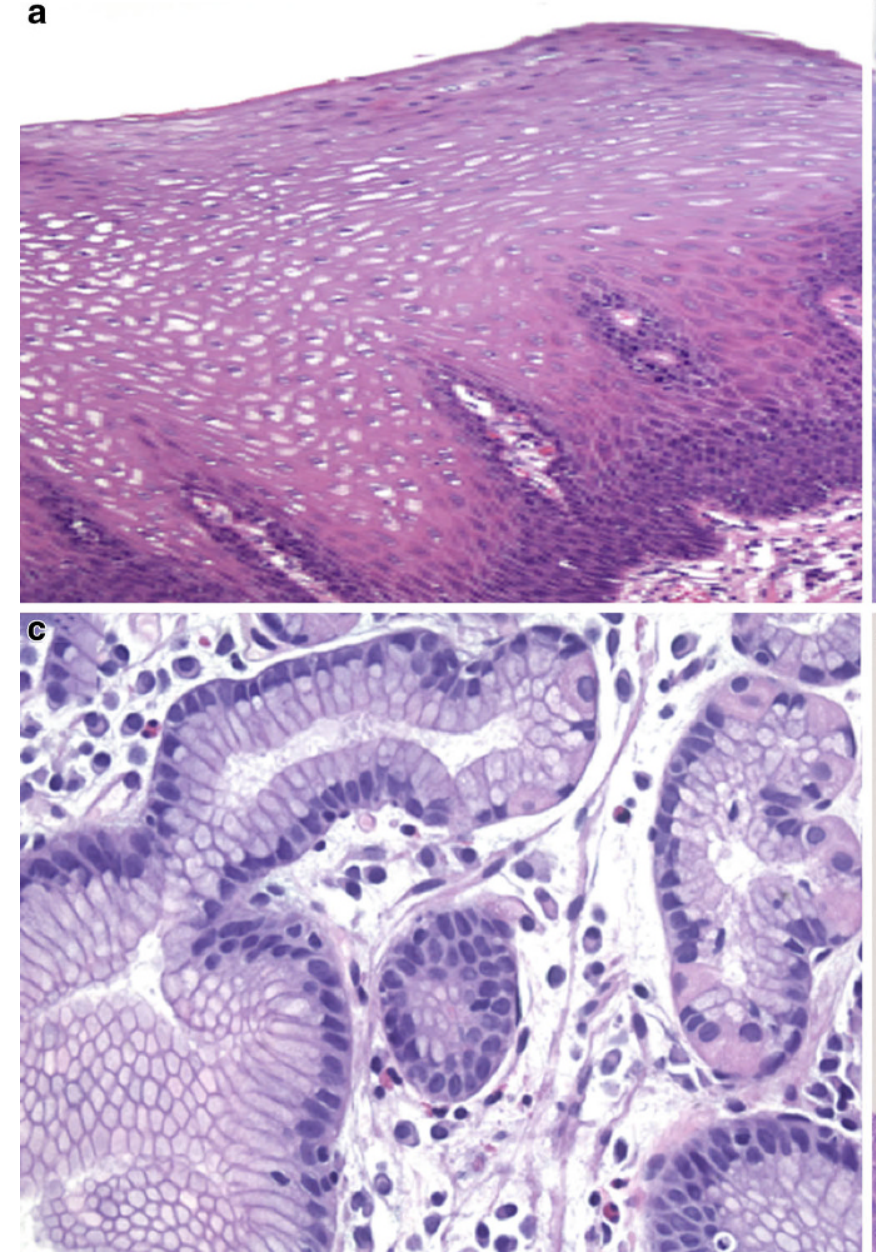

Fig. 3 Histopathology of normal squamous epithelium of the esophagus (a), cardiac mucosa (b), oxyntocardiac mucosa (c), and Barrett's esophagus (d). Panels $\mathbf{b}, \mathbf{c}, \mathbf{d}$ depict different forms of columnar lined esophagus according to the Chandra-

with the author's guess, these different forms of the machine- and mechanism-induced manifestations and translations of the above four fields are summarized and remembered within the term "heavens." You, dear reader, may ask, "What the hell should an academic surgeon, female, male, nurse, personal deal with these aspects of physics and quantum physics? " The answer is: it happens in man, in you, during your surgeries and the ions of your patients are the same as those distributed in the universe and those making up far out galaxies, as assessed by the Hubble telescope. Nothing else happens during sonography, computed tomography, magnetic resonance imaging, positron-emission scan, endoscopy, histopathology, open and minimally invasive surgery, medicine and disease management: you intercept the universe. Oncology harbors the largest economic possibilities and fosters the development of novel fruitful technologies, procedures, and tools at the cost of those who find time to reason about the essence of a disease, to allow reasoning to the common trunk mechanism of all socalled benign and malignant diseases (except trauma
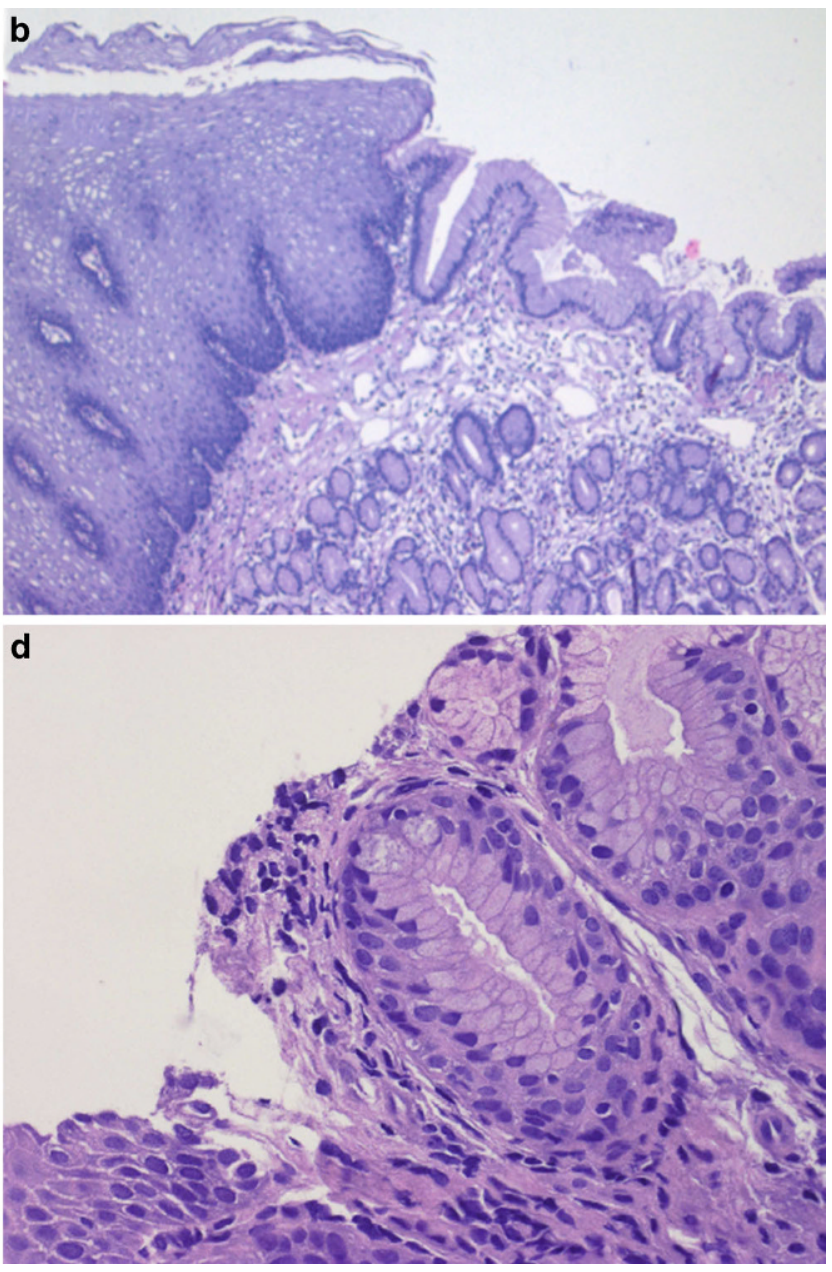

soma classification, i.e., epithelia which are formed as the consequence of increased gastroesophageal reflux, as outlined in the text. Thanks to the courtesy of Prof Dr Fritz Wrba, Vienna, Austria. H\&E stain

and injuries), i.e., genetically, hereditary mediated and lifestyle acquired intolerance against so-called concentrated sugar-(carbohydrate-)containing foods and beverages. We are what we eat, we are what we drink, smoke, and ganja. Discipline and humility foster wellbeing. Taken together, our perceptions result from the fragmented perspective resulting from our limited, partial interaction and interception with the four fields. The interaction of fields creates space, time, and the heavens. Does the understanding of such a scenario necessarily require the invention of a creator?

\section{Lessons learnt from the bullet of the gullet}

Going in line with the above considerations, woman and man follow the ruling opinion because it is easier, safer, and prevents confrontation, uprising, and active responsibility and increases the idea of survival. The majority does not want to take risk and responsibility. Next, we examine an example to show the effect and 
result of uncritical following and blind belief in a given ruling opinion and guideline in medicine [4-14].

Gastroesophageal reflux disease (GERD) represents an increasing lifestyle disease and affects $20-40 \%$ of our so-called Western civilization. Good morning burbs, mental and mind. Bili Rubin rocks gall stone delivery shine. Due to the symptoms and an increased cancer risk in those positive for Barrett's esophagus $(0.5 \%$ annual cancer risk), GERD impairs life quality and productivity $[4,5,10,11]$. Hereditary weak connective tissue and mechanical stressinduced (lifestyle, eating behavior, sports, pregnancy) distorted diaphragmatic anchorage and failure of the lower esophageal sphincter foster reflux of acid gastric content $[4,5,10]$. This in turn causes the symptoms and morphological consequences, i.e., columnar lined esophagus, premalignant Barrett's esophagus, esophageal cancer (adenocarcinoma) ([11-15]; Figs. 2 and 3). Although gastric acid is not the cause of GERD, i.e., the cause is the failure of the lower esophageal sphincter $[4,5,10]$, the ruling opinion guideline recommends acid blocker therapy (proton pump inhibitor, PPI) as the mainstay for GERD treatment ([4, 10]; Fig. 2). Surgical repair of the sphincter is only considered by the guidelines if PPI therapy fails to control the symptoms $[4,10]$. Furthermore, eradication of premalignant Barrett's esophagus is recommended for low- and high-grade dysplasia changes, but not for non-dysplastic Barrett's esophagus. Although it is well known that Barrett's esophagus develops as a consequence of failure of the lower esophageal sphincter, the ruling opinion does not recommend surgical repair of the sphincter. As a consequence, we had 30 cases of esophageal adenocarcinoma per year in Austria during the 1970s (the classical period of rock music, reggae \& roots); by 2010 there were approximately 400 cases per year, in 2019 we expect 800 cases per year. These numbers go in line with those observed in other countries of the EU (United Kingdom, France, Germany, Italy). Could it be allowed to consider the following? The dramatic rise in the frequency of reflux-induced cancer of the esophagus is due to the fact that our physicians blindly and uncritically followed the so-called pharmacy-, industry-, interest-driven ruling opinion guideline. Caesar always asked himself: cui bono? As such, the only winner of the game seems to be the medical industry (PPI!) [4]. In contrast, recent evidence indicates that effective anti-reflux surgery \pm ablation therapies prevents cancer development in Barrett's esophaguspositive GERD [10-14]. It seems that guidelines are valuable as fire, we have to take care not to get burnt, a burnt-out case. In addition, data indicate that the management of GERD and Barrett's esophagus should also consider lifestyle aspects and nutrition, i.e., the avoidance of food and beverages containing concentrated sugars and fostering a low-carb diet [15].

\section{Conclusion}

Taken together, let us critically question ruling opinions for the maintenance of wellbeing, productivity, and stability of our civilization. The only danger, which we cannot prevent, may be the environmental cataclysm due to an asteroid impact, floods, and earth quakes. The rest seems to be put into the responsibilities of our hands. As surgeons we know: do not leave the correct layer, otherwise you may get into trouble. Thus, let us know our anatomy and embryology. As such, the thyroid belongs to esophagus, as the ears belong to the head. They behave like brother and sister, like Isis and Osiris, like Orion and the great pyramid. Enjoy the legacies. Stay tuned.

Martin Riegler

Acknowledgements The author thanks his wife Tina, his father Ewald, the remembrance of his mother Friedhild; he thanks his sister Senta and her husband Peter and their children Matthias, Sebastian, and Anna, and his very few real friends for their great support during busy exciting times of beautiful change and productive innovation. The author thanks his teachers for having provided him with an exceptional teaching and education for a fundamental understanding of disease, and he thanks his patients for their confidence and for being allowed to learn about their complaints, diseases, sorrows, and pains. Finally, the author thanks all contributors and supporters of European Surgery. Otherwise, the project and the ideas presented herein, would not be possible.

Conflict of interest M. Riegler declares that he has no competing interests.

\section{References}

1. Musil R. Haus und Wohnung des Mannes ohne Eigenschaften. In: MusilR, editor. Der Mann ohneEigenschaften. Berlin: Rowohlt; 1930. pp. 13-6.

2. Zweig S. Incipit Hitler. In: Zweig S, editor. Die Welt von Gestern. Stockholm: Bermann Fischer; 1941.pp. 372-5.

3. Bernard T. In: Bernhard T, editor. Heldenpatz. Frankfurt: Suhrkamp; 1988. pp.97-8.

4. Chandrasoma PT. Definition od gastroesophageal reflux disease: past, present and future. In: Chandrasoma PT, editor. GERD, a new understanding. Elsevier: Academic Press; 2018. pp.3-22.

5. Labenz J, Chandrasoma PT, Knapp LJ, DeMeester TR. Proposed approach to the challengingmanagement of progressive gastroesophageal reflux disease. World J Gastrointest Endosc. 2018;10(9):175-83.

6. Hancock G. Sand. In: Hancock G, editor. Magicians of the gods. London: Coronet;2015. p. 1.

7. Kennett JP, Kennett DJ, Culleton BJ, et al. Bayesian chronological analyses consistent with synchronous age of 12.835-12.735 cal B.P. for younger dryas boundary on four continents. Proc Natl Acad Sci U S A. 2015; https://doi.org/ 10.1073/pnas.1507146112.

8. Kjaer KH, Larsen NK, Binder T, et al. A large impact crater beneath Hiawatha glacier in northwest greenland. Sci Adv. 2018;4:eaar 8173. 
9. Jomrich G, Hollenstein M, John M, et al. High mean corpuscular volume predicts poor outcome for patients with gastroesophageal adenocarcinoma. Ann Surg Oncol. 2019;26(4):976-85.

10. Schoppmann SF, Kristo I, Riegler M. Does anti reflux surgery disrupt the pathway of Barrett's esophagus progression to cancer? Transl Gastroenterol Hepatol. 2018;3:101.

11. Rieder E, Riegler M, Simic AP, et al. Alternative therapies for GERD: a way to personalized antireflux surgery. Ann N Y Acad Sci. 2018;1434(1):360-9.

12. Alicuben ET, Tatum JM, Bildzukewicz N, et al. Regression of intestinal metaplasia following magnetic sphincter augmentation device placement. Surg Endosc. 2019;33(2):576-9.

13. Zaninotto G, ParenteP, Salvador R, etal. Long termfollow up of Barrett's epithelium: medical versus antireflux surgical therapy. J Gastrointest Surg. 2012;16(1):7-14.

14. Riegler M, Kristo I, Nikolic M, et al. Update on the management of Barrett's esophagus in Austria. Eur Surg. 2017;49(6):282-7.

15. Riegler M, Kristo I, Asari R, et al. Dietary sugar and Barrett's esophagus. Eur Surg. 2017;49(6):279-81.

Publisher's Note Springer Nature remains neutral with regard to jurisdictional claims in published maps and institutional affiliations. 